\title{
Knowledge and Myths about Preeclampsia and Eclampsia and its influence on Antenatal Service Utilization among pregnant women and their male partners in Mtwara Region-Tanzania: A Cross Sectional Analytical Study.
}

Aziza Shaibu Machenje ( $\square$ gmachenje2@gmail.com )

The University of Dodoma College of Health Sciences https://orcid.org/0000-0001-8210-226X

Stephen M. Kibusi

The University of Dodoma College of Health Sciences

\section{Nyasiro Gibore}

The University of Dodoma College of Health Sciences

Athanase Lilungulu

The University of Dodoma College of Health Sciences

Fabiola V. Moshi

The University of Dodoma College of Health Sciences

\section{Research article}

Keywords: Myths, pregnant women and their male partners (expecting couples), ANC utilization, preeclampsia, eclampsia

Posted Date: December 3rd, 2020

DOl: https://doi.org/10.21203/rs.3.rs-32334/v2

License: (c) (i) This work is licensed under a Creative Commons Attribution 4.0 International License.

Read Full License 


\section{Abstract}

Background: Pregnancy induced hypertension, including preeclampsia and eclampsia are the major health problem and the main cause of the maternal and perinatal morbidity and mortality in Tanzania. The aim of this study was to assess knowledge and myths about preeclampsia and eclampsia and its influence in Antenatal Clinics (ANC) utilization among pregnant women and their male partiners in Mtwara region.

Method: A community based cross-sectional analytical study conducted in Mtwara Region, a random sampling procedure was employed to obtain a sample size of 384 pregnant women and their male partners a total of 768 participants (male=384 and female $=384$ ). Interviewer structured questionnaire was used for data collection and Statistical package for social science (SPSS v.20) software was used for data entry and analysis. Descriptive statistics, cross tabulation, Principal component analysis (PCA) was conducted and inferential statistics were used to test association between variables obtained.

Results: Among 768 participants, male partners 167(43.5\%) and pregnant women 171 (44.5\%) had adequate knowledge about preeclampsia and eclampsia. More than a half 396(51.6\%) of study respondents had weak myths while 372(48.4\%) had strong myths on pre-eclampsia and eclampsia. Furthermore, pregnant women $244(64 \%)$ had adequate antenatal care utilization. Study participants who had adequate knowledge on pre-eclampsia and eclampsia were almost 3 times more likely to utilize antenatal care services $(A O R=2.827 ; \mathrm{Cl}=1.719-4.651 ; \mathrm{p}<0.001)$. Study participants who had weak myth on pre-eclampsia and eclampsia were less likely to have adequate antenatal care attendance (AOR= $0.370 ; \mathrm{Cl}=0.229 ; \mathrm{p}<0.001)$

Conclusion : The overall knowledge of preeclampsia and eclampsia was low. Majority of the female had adequate antenatal service utilization. Majority of respondents had weak myths. Government and stakeholders should ensure that community is equipped with knowledge about preeclampsia and eclampsia and the available Myths should be dispelled.

\section{Plain English}

One of the parameters which is monitored during antenatal visits is pregnant women's blood pressure. The blood pressure recorded during the first visit is used as an indicator of increased blood pressure. Preeclampsia is a condition in pregnancy characterized by high blood pressure, sometimes with fluid retention and protein in urine. Eclampsia is a severe condition of preeclampsia in which one or more convulsions occur in a pregnant suffering from high blood pressure, often followed by coma and posing a threat to the health of mother and baby.

The study aimed to find out the relationship between knowledge on preeclampsia and eclampsia on antenatal attendance among pregnant women and their male partners in low resources setting of Mtwara Region Tanzania. The study was done among community with high prevalence of eclampsia. The nant women's blood pressure is not well monitored. One 
expects the signs and symptoms of preeclampsia to be diagnosed during antenatal visits and proper management to be initiated so that it won't develop into a serious condition (eclampsia). The only window for monitoring the blood pressure is antenatal attendance.

The study also worked out the influence of knowledge and myth about preeclampsia and eclampsia on antenatal attendance. The local beliefs on the causes of preeclampsia and eclampsia may influence the use of health facility for management. If couples believe preeclampsia and eclampsia are caused by evil spirits, it is obvious the intervention will focus on traditional healers.

\section{Introduction}

Globally the Millennium development goals report shows that from 1990 to 2013 there was a decline of maternal deaths by $45 \%(289,000)$ per year[1]. However about 830 women died every day due to pregnancy complications or during delivery in 2015 , meanwhile, perinatal mortality accounts for $40 \%$ of infants globally[2]. So far, in Sub-Sahara 179000 women die each year during pregnancy and childbirth[1]. According to the Tanzania Demographic Health Survey, the maternal mortality ratio accounts for 556 deaths per 100,000 live births while the perinatal mortality rate showed 39 deaths per 1000 pregnancies[3].

Pregnancy induced hypertension is a sign of underlying pathology which appears for the first time during pregnancy and it is a common medical complication of pregnancy[4]. Pregnancy induced hypertension , including preeclampsia and eclampsia, are the major health problem and the main cause of the maternal and perinatal morbidity and mortality. Tanzania, the incidence of preeclampsia and eclampsia found to be $1.7 \%[5]$. According to the Tanzania Demographic Health survey, it shows that pregnancy induced hypertension is the second leading cause of maternal mortality which accounts for $19 \%$ of death[3]. To reduce the problem, the government set many strategies to ensure that the objectives are met. According to the Health sector strategic planning (HSSP IV) 2015- 2020 period, the following should be achieved: increasing skilled birth attendance by $80 \%$, continue to expand provision of quality services during pregnancy, childbirth, and postnatal period, provision of Basic Emergency Obstetric and Newborn care (BEmONC) and Comprehensive Emergency Obstetric and Newborn care (CEMONC), also by the end of $2020,70 \%$ of primary health facilities provide BEmONC and $50 \%$ of health centres and $100 \%$ of Hospitals provide CEMONC, also to ensure community awareness activities reach every household to achieve SDGs $4 \& 5[6]$.

There are several factors that lead to the high maternal and perinatal morbidity and mortality in the Global south such as Tanzania and the reasons are very crucial[7]. In the community perspectives, many factors involved such as knowledge gaps, myths regarding preeclampsia and eclampsia, traditional beliefs and inaccessibility of health care services during pregnancy[8]. Lack of knowledge, myths about danger signs of pregnancy makes the family not to put into considerations the early signs and symptoms of preeclampsia and eclampsia as a results delay to seek health care services [8]. 
So far, Men in Tanzania have inadequate knowledge regarding reproductive issues compared with women[9]. In turn men are the decision maker in all matters related to family issues including health services utilization which bring a negative impact on the maternal and perinatal outcome[10]. Moreover, empowering men with essential information on emergency obstetric condition such as preeclampsia and eclampsia is a vital strategy towards utilization of services in reducing maternal and perinatal morbidity and mortality [11].

Previously study done in Makole Ward Dodoma Tanzania about knowledge of preeclampsia among women results revealed $41 \%$ had a low level of knowledge about preeclampsia and eclampsia, half of the respondents agreed that the disease is due to evil spirit and exposure to fire while the remaining disagreed[12]. Another study done in Same District Hospital, the results showed that only $40 \%$ had knowledge of preeclampsia while the majority $(60 \%)$ had no knowledge[13].

A study was done in Sindh Pakistan, the findings of the study revealed that preeclampsia was not recognized as a disease; however, women were aware of high blood pressure and can develop during pregnancy. Women believed that stress and weakness were conditions that cause high blood pressure and headache during pregnancy. [14].

Little is known on the knowledge and myth on pre-eclampsia and eclampsia and its influence in antenatal attendance in rural community of Tanzania.

\section{Methods}

Study area

This study was conducted in Mtwara region. The Region covers the total area of $16,710 \mathrm{~km}^{2}$ (6,450sqmi). Administratively the Region divided into nine districts that are Mtwara Municipal, Newala DC, Tandhimba, Masasi DC, Nanyumbu, Masasi TC, Mtwara DC, Newala TC, and Nanyamba TC. The region has a total of 253 health facilities among those 6 Hospitals, 22 Health centres and 225 Dispensaries Almost all facilities are providing ANC services like physical examination of pregnant women, Health education about danger signs of pregnancy, testing and counseling for HIV/AIDS, Vaccination of Tetanus toxoid, micronutrients provision and checking for Hemoglobin level etc.

Study design

A community based analytical cross sectional study was conducted. The study employed a quantitative research approach. This design was chosen so as to assess the community myths about preeclampsia and eclampsia towards Antenatal services utilization. 
The study involved 4 districts namely Mtwara DC, Newala, Nanyumbu, and Masasi. In each District two wards were involved, making a total of eight wards, At village level three villages from each ward were involved making a total of 24 villages.

Study population

Pregnant women who were in second and third trimester with their Male partners. This group was at risk group for preeclampsia and eclampsia since the women were pregnant and were the one who expected to utilize ANC services. Furthermore male partners are the decision maker in family level even regarding the health of their spouse.

Sample size calculation

Since there was no any documented study done in Mtwara Region showing the prevalence of preeclampsia and eclampsia, hence, this study used a prevalence of $50 \%$ as a standard to calculate the sample size. By using the Kish Leslie formula as follows: -

$\mathrm{N}=\underline{\mathrm{Z}} \underline{\underline{2}} \underline{\mathrm{xP}}(\underline{100-\mathrm{P}})$.

$\mathrm{E}^{2}$

Whereby

$\mathrm{N}=$ sample size

$\mathrm{Z}=$ Confident interval to $95 \%$ (1.96)

$\mathrm{P}=$ Prevalence $(50 \%)$

$\mathrm{E}=$ Worst acceptable margin error (0.05)

HENCE:

$\mathrm{N}=(\underline{1.96}) \underline{\underline{2}} \underline{\mathrm{x} 50 / 100}(\underline{100-50 / 100})$.

$(0.05)^{2}$

$\mathrm{N}=384.16$. Therefore the sample size was 384 couples. Pregnant women and their male partiners. The total participants 768

Sampling technique

The region was selected purposively because of an increasing number of preeclampsia and eclampsia and women reported at the health facility while already had eclamptic fit as seen earlier in $\mathrm{RCH}$ report of 2018. Then districts, wards, and villages employed multistage sampling. Mtwara Region has nine districts namely Mtwara municipal, Mtwara district, Masasi district, Newala district, Nanyumbu district, Masasi Town council, Newala Town council, Tandahimba district Council and Nanyamba Town Council. The main indigenous ethnir ornuns in Mtwara Rerrion are Makonde, Makua, Yao, Wamatambwe and Mwela. Loading [MathJax]/jax/output/CommonHTML/jax.js 
Makonde is the dominant tribe which is found in all councils except Nanyumbu DC Makonde tribe made 70\% of the Population (TDHS, 2015) . Generally the people of Mtwara Region share the same characteristics due to their ethinic origin.

\section{Table 1: Major Tribes by Council, Mtwara Region, 2015}

\begin{tabular}{|l|l|l|}
\hline S/N & Councils & Major Ethnicity Groups \\
\hline 1 & Mtwara District & Makonde \\
\hline 2 & Newala DC & Makonde \\
\hline 3 & Masasi District & Makua, Yao and Makonde \\
\hline 4 & Tandahimba DC & Makonde and Makua \\
\hline 5 & Mtwara-Mikindani MC & Makonde, Mwela, Yao and Makua \\
\hline 6 & Nanyumbu DC & Makua and Yao \\
\hline 7 & Masasi TC & Makua, Makonde, Mwela and Yao \\
\hline 8 & Nanyamba TC & Makonde \\
\hline 9 & Newala TC & Makonde \\
\hline
\end{tabular}

The first stage was a selection of four Districts (Mtwara DC, Nanyumbu, Newala and Masasi DC) out of nine districts within Mtwara Region. Simple random sampling using the lottery method was used to select the districts. A list of all districts was obtained and the names of the districts were listed. Pieces of paper were divided according to the number of districts and the names of the district were written in each small piece of paper then each piece of paper was folded and put together in a box. Then the box was shaken and four pieces were picked at random and names of districts were identified. The second stage was a selection of wards whereby all wards in each district (21 Wards of Mtwara DC, 17 Wards of Nanyumbu district, 22 Wards of Newala district and 34 Wards of Masasi district) were listed. By using the lottery method two wards from each district were selected randomly to obtain a total of 8wards. The third stage was selection of three villages from each selected ward by repeating the same procedure to obtain a total of 24 villages. The fourth stage was a selection of participants from each village whereby a list of pregnant women with gestation age of 24 weeks and above who lived with a male partner was obtained from a ten cell leader and eligible participants were given a number, thereafter by the use of lottery method simple random procedure was employed to select 16 expecting couples who met inclusion criteria from each village. 
All pregnant women including prime gravid and multigravid who were in the second and third trimester, gestation age of 24 weeks and above who lived together with their male partners who were willing to participate in the study. These groups provided valid information on their knowledge and myths about preeclampsia and eclampsia.

\section{Exclusion criteria}

Pregnant women and their partners who were very sick, mentally incapability and who refused to be involved in this study

Research instruments

The tool used to collect data was a structured questionnaire, with closed ended questions and open-ended questions. The questionnaire was divided into four sections. Socialdemographic and social economic characteristics, questions for measuring knowledge, myths and Antenatal service utilization.

Social demographic and social economic characteristics adapted from NBS, 2015. The questions were translated in Swahili language and the whole questionnaire took 30 minutes to complete.

\section{Data collection process.}

Data were collected through interviewer structured questionnaires. A researcher together with research assistants interviewed the eligible respondents whereby the researcher and research assistant filled the questionnaire the response from the participants. Ten research assistants were involved in data collection after being trained before the process commenced.

Data processing and analysis

Data obtained were coded manually and then were entered into the computer and cleaned. Data analysis was finally done by using statistical package for the social sciences (SPSS) computer software version 20. Frequencies and cross tabulations were done. Data were summarized into frequency tables, figures and chi square was done to look for an association between demographic variable and outcome variables. Logistic regressions were used to determine the strength of association between selected variables and outcome variable. Moreover, a P-value and confidence interval used to verify the significance of the differences found. A P-value $<0.05$ was considered to be statistically significant. The principal component analysis was also done to find out the weighted score of the questions Loading [MathJax]/jax/output/CommonHTML/jax.js egarded as relevant. 


\section{Measurements of the variables.}

Level of knowledge about preeclampsia and eclampsia.

Knowledge on preeclampsia and eclampsia was measured by nominal scale involved 38 items on knowledge with yes/no answers which were then converted into correct and incorrect. Unnecessary questions were rejected and remaining with 11 questions for analysis. Then one score for each correct answer and zero score for each wrong answer (Savage \& Hoho, 2016). Therefore those who scored 50\% and above were termed as having adequate knowledge and below 50\% inadequate knowledge.

Myths on preeclampsia /eclampsia

Questionnaires adapted and modified from (Boene et al., 2016). This involved with 6 open ended questions which made a total of 32 responses regarding myths on preeclampsia and eclampsia. Difference responses were obtained from the respondents. Similar responses were grouped and then coded and 32 responses obtained. Therefore myths was measured by employing principle component analysis

Myths were computed by using principal component analysis (PCA). The first analysis was done to 32 responses regarding myths and to give weight to each question. During analysis 14 components were obtained and component one was selected since had a high variance of 9.674. 21 responses had weight less than 0.3 therefore excluded from the component matrix and 11 responses remained. The second analysis was involved with 11 responses and four (4) components obtained whereby the variance of the component one raised from 9.674 to 23.627. All 11responses weighted above 0.3 and no question was excluded from the matrix. Responses which excluded from the component matrix as shown in table 2 .

Table2: Questions about Myths used in PCA ( $\mathrm{N}=32 \mathrm{Qns})$. 
Principal component

analysis (PCA)

First

Second

analysis

analysis

The local name for preeclampsia and eclampsia is devil disease

$-0.284 *$

The local name for preeclampsia and eclampsia is mental illness

0.572

0.489

The local name for preeclampsia and eclampsia is God-made

$0.046^{*}$ disease

The local name for preeclampsia and eclampsia is magic disease

$-0.180 *$

The local name for preeclampsia and eclampsia is big illness

$0.238 *$

The local name for preeclampsia and eclampsia is Homa ya

$-0.104^{*}$

mdudu

The local name for preeclampsia and eclampsia is illness of the

$-0.238 *$ moon

Causes of preeclampsia and eclampsia is devils living in the wild,

0.428

0.344 sea \&big trees

Causes of preeclampsia and eclampsia is Witch craft

$-0.155^{*}$

Causes of preeclampsia and eclampsia is Mnyama(animal)

$-0.185^{*}$

Causes of preeclampsia and eclampsia is mistreatment by in-law

$-0.183^{*}$

Presentation of preeclampsia and eclampsia is convulsions

$0.074 *$

(kukwijula)

Presentation of preeclampsia and eclampsia is eye rolling back

0.515

0.543

Presentation of preeclampsia and eclampsia is miso makasuku

$0.138^{*}$

(red eye)

Presentation of preeclampsia and eclampsia is Chidudu

0.273*

(headache)

Presentation of preeclampsia and eclampsia is chakare( regular

$-0.453$

$-0.585$

falling)

Presentation of preeclampsia and eclampsia is Lyuni ( Dizziness)

$-0.183^{*}$

Presentation of preeclampsia and eclampsia Kyokombe (heart

$-0.220 *$

burn)

The consequence of preeclampsia and eclampsia is premature

0.509

0.474

baby (njiti)

The consequence of preeclampsia and eclampsia is kuyiwa (loss

0.198*

of memory)

The consequence of preeclampsia and eclampsia is death of the

0.059* mother

The consequence of preeclampsia and eclampsia is mental illness

$0.072 *$

The consequence of preeclampsia and eclampsia Litulilye

$-0.643$

$-0.601$ 
Principal component

analysis (PCA)

First Second

analysis

$-0.274^{*}$

Treatment of preeclampsia and eclampsia is drinking boiled green tree

Treatment of preeclampsia and eclampsia is special dance to expel demons/devils

Treatment of preeclampsia and eclampsia is burning leaves or incense (ubani)

Treatment of preeclampsia and eclampsia splashing human urine over the mother' body with eclampsia

Prevention of preeclampsia and eclampsia locally is tie a string of tree around the waist

Prevention of preeclampsia and eclampsia locally is wear charms (hirizi) around the neck

Prevention of preeclampsia and eclampsia locally is wear a black piece of cloth around the wrist

Prevention of preeclampsia and eclampsia locally is boil the wood of the trees and bathe

Prevention of preeclampsia and eclampsia locally lie the pregnant mother under the bed.
$-0.395 \quad-0.521$

0.380

0.371

0.379

0.329

0.331

0.430

$0.064 *$

$0.176^{*}$

$-0.431$

0.563

$-0.184^{*}$

Source: Researcher field data.

Key: * Responses excluded from the component matrix.

After PCA normality test was done and data were not normally distributed. Then the computed Mean= -0.0866278; Median = -0.1694712; Mode = -0.18007; Standard deviation $=0.79491721 ;$ Range $=4.55206 ;$ Min $=-2.31358 ; \operatorname{Max}=2.23843$. To categorize myths median was used as a cutoff point so as to get those who had strong Myths and those who had weak Myths about preeclampsia and eclampsia below the median weak Myth and above the Median strong Myth.

Antenatal service utilization 
Involved 7 items adapted and modified from (Doe, 2013). In Tanzania pregnant woman should attend Antenatal clinic at least four visits if she has no any problem until delivery. Therefore from 24 weeks the woman could have 2 visits if she really started clinic in time which helped me to measure ANC utilization. First visit started when woman has gestation age of below 16 weeks, second visit 20 to 24 weeks, third visit 26 to 28 weeks and fourth visit 28 to 36 weeks. In inclusion criteria of 24 weeks and above this woman obviously attended ANC clinic not less than two visits. Therefore utilization was measured by number of recommended antenatal visits by WHO guideline. Therefore if the women attended ANC less than two visits was graded as inadequate utilization of ANC services and if attended two or more visits graded as adequate utilization of ANC service. (Hijazi, Alyahya, Sindiani, Saqan, \& Okour, 2018).

\section{Results And Discussion}

\section{Results}

Social- demographic characteristics of the participants.

The study involved 384 couples who met inclusion criteria. Among them, female were 384 and male also were 384 which made a total of 768 participants. Results indicated that Majority of the participants 270 (36.0\%) were in the age group, The mean age was 31.71士 8.056, median age 30.00, minimum age 18 and maximum age was 59. Regarding the education level of the participants, the large proportion of respondents $465(60.0 \%)$ had primary education and a small proportion 92 (12.5\%) had secondary education. Majority of the participants 665 (84\%) were peasants and those who had three or more children were 260 33.9\%). Majority of the participants 605 (78.0\%) had an income of less than 1000 T.shs per day. Large proportion 599 (78.0\%) were able to access health facility when they face problems. (Table 3).

Table 3: Social-demographic distribution of the participants $(\mathrm{N}=768)$ 


\begin{tabular}{|c|c|c|}
\hline Variable & Frequency $(\mathrm{n})$ & Percentage (\%) \\
\hline \multicolumn{3}{|l|}{ Age group } \\
\hline $18-25$ & 197 & 25.0 \\
\hline $26-33$ & 270 & 36.0 \\
\hline $34-41$ & 188 & 24.0 \\
\hline $42+$ & 113 & 15.0 \\
\hline \multicolumn{3}{|l|}{ Sex } \\
\hline Male & 384 & 50.0 \\
\hline Female & 384 & 50.0 \\
\hline \multicolumn{3}{|l|}{ Education level } \\
\hline No formal education & 211 & 27.5 \\
\hline Primary & 465 & 60.5 \\
\hline Secondary & 92 & 12.5 \\
\hline \multicolumn{3}{|l|}{ Occupation } \\
\hline Employed & 16 & 2.1 \\
\hline Unemployed & 61 & 7.9 \\
\hline Self employed & 46 & 6.0 \\
\hline Peasant & 665 & 84.0 \\
\hline \multicolumn{3}{|l|}{ Religion } \\
\hline Christian & 161 & 21.0 \\
\hline Muslim & 607 & 79.0 \\
\hline \multicolumn{3}{|l|}{ Ethnicity } \\
\hline Makonde & 285 & 37.1 \\
\hline Makuwa & 335 & 43.6 \\
\hline Yao & 82 & 10.7 \\
\hline Others & 66 & 8.6 \\
\hline \multicolumn{3}{|l|}{ Number of children } \\
\hline One & 162 & 21.1 \\
\hline Two & 193 & 25.1 \\
\hline Three or more & 260 & 33.9 \\
\hline None & 153 & 19.9 \\
\hline \multicolumn{3}{|c|}{ Access to health facility } \\
\hline Yes & 599 & 78.0 \\
\hline No & 169 & 22.0 \\
\hline \multicolumn{3}{|c|}{ Distance to health facility } \\
\hline$<$ than 5 Kilometer & 586 & 76.3 \\
\hline >than 5 Kilometer & 182 & 23.7 \\
\hline \multicolumn{3}{|l|}{ Daily income } \\
\hline <than 1000 T.shs & 605 & 78.8 \\
\hline x/output/CommonHTML/jax.js & 163 & 21.2 \\
\hline
\end{tabular}


Level of knowledge about preeclampsia and eclampsia among pregnant women and their male partners

Majority of respondents 217(56.5\%) male and 213(55.5\%) female had inadequate knowledge on pre-eclampsia and eclampsia, only 167(43.5) of male partners and 171(44.5) of pregnant women had adequate knowledge on pre-eclampsia and eclempsia (figure 1)

Responses to specific questions involved in assessing knowledge on pre-eclampsia and eclampsia

Majority of both pregnant women 248(64.6\%) and their male partners 220(57.3\%) did not know whether pre eclampsia is a hypertensive disorder; majority of them did not respond correctly on the risk factors of preeclampsia [268(69.8\% of pregnant women and 302(78.6) did not know whether pre existing history of high blood pressure can lead to pre eclampsia]; Also majority of respondents failed to repond correctly on the signs of preeclampsia [201(52.3\%) of pregnant women and 198(51.6) responded incorrectly on severe headache; 285(74.2\%) of pregnant women and 269 (70.1\%) on visual disturbance ] Table 4

Table 4: Responses to specific questions involved in assessing knowledge on pre-eclampsia and eclampsia 


\begin{tabular}{lcc}
\hline Variable & Pregnant Women & Male partners \\
& Frequency & Percent \\
& Frequency Percent \\
\hline
\end{tabular}

Preeclampsia is Hypertension in Pregnancy

Correct response

Incorrect response

Risk factor for preeclampsia is history of

high blood pressure before conception
Correct response

Incorrect response

Risk factor for preeclampsia is Overweight

Correct response

Incorrect response

Symptom of preeclampsia is severe

headache

Correct response

Incorrect response

Symptom of preeclampsia is Increase urine

out put

Correct response

Incorrect response

Symptom of preeclampsia is Visual

disturbance

Correct response

Incorrect response

Symptom of preeclampsia is Epigastric pain

( central just below the ribs

Correct response

Incorrect response

Symptom of preeclampsia is Sudden swelling

of the face, hands or feet

Correct response

Incorrect response

Sign of preeclampsia is Convulsions(fits)

Correct response

Incorrect response

Sign of preeclampsia is Loss of consciousness

Correct response

Incorrect response

Loading [MathJax]/jax/output/CommonHTML/jax.js

$\begin{array}{llll}136 & 35.4 & 164 & 42.7 \\ 248 & 64.6 & 220 & 57.3\end{array}$

116

30.2

82

21.4

268

69.8

302

78.6

152

39.6

116

30.2

232

60.4

268

69.8

183

47.7

186

48.4

201

52.3

198

51.6

240

144

62.5

204

180

53.1

37.5

46.9

99

285

25.8

115

269

29.9

70.1

74.2

131

34.1

125

32.6

253

65.9

259

67.4 
death

Correct response

68.5

249 64.8

\section{Complication of preeclampsia is Fetal death}

\begin{tabular}{lcrrr} 
Correct response & 193 & 50.3 & 169 & 44 \\
\hline Incorrect response & 191 & 49.7 & 215 & 56 \\
\hline Use of salt free diet & & & & \\
\hline Correct response & 194 & 50.5 & 139 & 36.2 \\
\hline Incorrect response & 190 & 49.5 & 245 & 63.8 \\
\hline
\end{tabular}

The relationship between socio-demographic characteristics and level of knowledge

The variable which showed significant relationship with knowledge were employment status $(p<0.001)$, ethnicity $(p<0.001)$, parity $(p<0.001)$, access to health facility $(p<0.001)$, walking distance to a nearby health facility $(p<0.001)$ and access to mobile phone $(\mathrm{p}=0.004)$ Table 5

Table 5: The relationship between socio-demographic characteristics and level of knowledge 


\begin{tabular}{|c|c|c|c|c|}
\hline Variable & $\begin{array}{l}\text { Adequate } \\
\text { knowledge } n(\%)\end{array}$ & $\begin{array}{l}\text { Inadequate } \\
\text { knowledge } \mathrm{n}(\%)\end{array}$ & $\mathrm{X}$ & $\begin{array}{l}\text { P- } \\
\text { Value }\end{array}$ \\
\hline \multicolumn{5}{|l|}{ Education level } \\
\hline No formal education & $86(40.8)$ & $125(59.2)$ & & \\
\hline Primary & $211(45.4)$ & $254(54.6)$ & & \\
\hline Secondary & $41(44.6)$ & $51(55.4)$ & $1.269 \mathrm{a}$ & 0.53 \\
\hline \multicolumn{5}{|l|}{ Occupation } \\
\hline Employed & $10(62.5)$ & $6(37.5)$ & & \\
\hline Unemployed & $20(32.8)$ & $41(67.2)$ & & \\
\hline Self employed & $9(19.6)$ & $37(80.4)$ & & \\
\hline Peasant & $299(46.4)$ & $346(53.6)$ & $17.934 a$ & $<0.001$ \\
\hline \multicolumn{5}{|l|}{ Religion } \\
\hline Christian & $63(39.1)$ & $98(60.9)$ & & \\
\hline Muslim & $275(45.3)$ & $332(54.7)$ & $1.969 \mathrm{a}$ & 0.161 \\
\hline \multicolumn{5}{|l|}{ Ethinicity } \\
\hline Makonde & $85(29.8)$ & $200(70.2)$ & & \\
\hline Makuwa & $167(49.9)$ & $168(50.1)$ & & \\
\hline Yao & $39(47.6)$ & $43(52.4)$ & & \\
\hline Others & $47(71.2)$ & $19(28.8)$ & $48.151 \mathrm{a}$ & $<0.001$ \\
\hline \multicolumn{5}{|l|}{ Parity } \\
\hline One & $52(32.1)$ & $110(67.9)$ & & \\
\hline Two & $73(37.8)$ & $120(62.2)$ & & \\
\hline Three or more & $125(48.1)$ & $135(51.9)$ & & \\
\hline none & $88(57.5)$ & $65(42.5)$ & $25.397 a$ & $<0.001$ \\
\hline \multicolumn{5}{|l|}{ Access to $\mathrm{H} / \mathrm{F}$} \\
\hline Yes & $286(47.7)$ & $313(52.3)$ & & \\
\hline No & $52(30.8)$ & $117(69.2)$ & $15.417 \mathrm{a}$ & $<0.001$ \\
\hline \multicolumn{5}{|l|}{$\begin{array}{l}\text { Walking distance to a } \\
\text { nearby H/F }\end{array}$} \\
\hline Less than $5 \mathrm{KM}$ & $287(49)$ & $299(51)$ & & \\
\hline $5 \mathrm{Km}$ or more & $51(28)$ & 131(72) & $24.745 a$ & $<0.001$ \\
\hline \multicolumn{5}{|l|}{ Sex } \\
\hline Male & $167(43.5)$ & $217(56.5)$ & & \\
\hline Female & $171(44.5)$ & $213(55.5)$ & $.085 a$ & 0.771 \\
\hline \multicolumn{5}{|l|}{ Own Mobile phone } \\
\hline No & $52(34.2)$ & $100(65.8)$ & & \\
\hline Yes & $286(46.6)$ & $328(53.4)$ & 7.561 & 0.004 \\
\hline
\end{tabular}

Predictors of knowledge on pre eclampsia and eclampsia

After controlling for confounders, predictors of knowledge were occupation status [Unemployed AOR=0.17at 95\% CI=0.049-0.592, $\mathrm{p}=0.005$; self employed AOR=0.095 at 95\% $\mathrm{CI}=0.024-0.373, \mathrm{p}=0.001$ ]; Ethnicity [Makuwa $\mathrm{AOR}=2.814$ at 95\% $\mathrm{CI}=1.944$ 4.074, $\mathrm{p}<0.001$; Yao $\mathrm{AOR}=5.48$ at 95\% CI=2.977-10.086, $\mathrm{p}<0.001$; Others $\mathrm{AOR}=4.902$ at Loading [MathJax]/jax/output/CommonHTML/jax.js Parity $\quad[$ One $\quad \mathrm{AOR}=0.344$ at $\quad 95 \% \quad \mathrm{CI}=0.203-$ 
0.584, $\mathrm{p}<0.001$; Two AOR $=0.4$ at $95 \% \mathrm{CI}=0.239-0.668, \mathrm{p}<0.001$ ]; Walking distance [5km or more $\mathrm{AOR}=0.093$ at $95 \% \mathrm{CI}=0.02 \quad-0.434, \mathrm{p}=0.003$ ] Table 6

Table 6: Predictors of knowledge on pre eclampsia and eclampsia

\begin{tabular}{lrrrrr}
\multicolumn{1}{c}{ Variable } & \multicolumn{3}{c}{$95 \%$ CI } & p-value \\
\cline { 2 - 5 } Occupation & AOR & Lower & Upper & \\
Employed & & & & & \\
Unemployed & 0.17 & 0.049 & 0.592 & 0.005 \\
Self employed & 0.095 & 0.024 & 0.373 & 0.001 \\
\hline Peasant & 0.518 & 0.171 & 1.57 & 0.245
\end{tabular}

\section{Ethinicity}

Makonde

Makuwa

2.814

Yao

5.48

1.944

$4.074<0.001$

Others

4.902

2.977

$10.086<0.001$

\section{Parity}

None

1

One

0.344

0.4

2.599

$9.244<0.001$

Two

0.203

$0.584<0.001$

Three or more

Access to $\mathrm{H} / \mathrm{F}$

Yes

No

0.239

$0.668<0.001$

Walking distance to a nearby $\mathrm{H} / \mathrm{F}$

Less than 5KM

$5 \mathrm{Km}$ or more

Yes

No
0.689

\section{1}

4.518

1
0.093 1

$0.426 \quad 1.116$

0.13 (1) 
consequence of preeclampsia and eclampsia, 392 (51.0\%) reported mental illness while 192 (25.0\%) reported intrauterine fetal death (Litulilye). (Table 7)

Table 7: Myths about preeclampsia and eclampsia $(\mathrm{N}=768)$ 
Local name for preeclampsia and eclampsia

The devil disease

Snake illness

God-made disease

Magic disease

41

5.3

Big illness

102

13.3

Homa ya mdudu

12

1.6

Illness of the moon

92

12

105

13.7

\section{Myths regarding the cause of preeclampsia and eclampsia}

Devils living in the wild, sea and big trees.

Witch craft

Mnyama (animal)

Mistreatment by in-law

The consequence of preeclampsia \& eclampsia

Njiti (Premature baby)

Loss of memory (Kuyiwa)

Death of the mother

Mental illness

50

6.5

Litulilye (intrauterine fetal death)

\section{Local treatment of preeclampsia and eclampsia}

Drinking boiled green leaves.

Special dance to expel demons/devils

Burning leaves or incense (kufukiza ubani)

Splashing of human urine over the mother`s body with 190 eclampsia. 


\section{Local prevention of preeclampsia and eclampsia}

Tie string of tree on the waist

Wear charms- (Hirizi) around the neck

173

22.5

Wear of black clothe on the hand

Boil the wood of trees and bathe

181

23.6

Lie the pregnant mother under the bed.

\section{Myths about preeclampsia and eclampsia}

The results showed that $51.6 \%$ had weak Myths and $48.4 \%$ had strong Myths about preeclampsia and eclampsia. Figure 2

\section{Antenatal care service utilization.}

The current study was also assessed ANC utilization among expecting mothers in Mtwara region $\mathrm{N}=384$. ANC utilization was defined as adequate if the women had at least two visits or more otherwise was inadequate keeping in mind that the current study dealt with the women who were in second and third trimester with the gestation age of 24 weeks and above together with their male partners. The total female participants were 384 and their findings regarding ANC services revealed that majority 244 (64\%) had an adequate utilization since they attended two or more visits and 140 (36\%) had an inadequate utilization as they attended less. Figure 3.

\section{Association between the level of knowledge and antenatal care service utilization.}

A Chi-square was done to show the relationship between knowledge and antenatal care services utilization then bivariate and Multivariate logistic regression was done. The findings showed that those who had adequate knowledge were all most 3 times more likely to utilize antenatal services compared to those who had inadequate knowledge (AOR = 2.827; $\mathrm{CI}=1.719,4.651 ; \mathrm{P}=0.000$ ). Also those who had three or more children were 2 times more likely to utilize ANC services compared to those who had no children (AOR = 2.148; $\mathrm{CI}=1.030,4.483 ; \mathrm{P}=0.042$ ). Other factors showed no association. More details as shown in table 8. 
Table 8: Multivariate logistic regression between knowledge level about preeclampsia and eclampsia and ANC utilization $(\mathrm{N}=384)$.

\begin{tabular}{lllll} 
Variable & AOR & p-value & \multicolumn{2}{c}{$\mathbf{9 5 \%}$ confident interval } \\
& & & Lower & upper \\
\hline Knowledge & & & & \\
\hline Adequate & $\mathbf{2 . 8 2 7}$ & $\mathbf{0 . 0 0 0}$ & 1.719 & 4.651 \\
\hline Inadequate(Ref) & & & & \\
\hline Occupation & & & & \\
\hline Employed & 0.490 & 0.480 & 0.068 & 3.547 \\
\hline Unemployed & 0.891 & 0.805 & 0.357 & 2.225 \\
\hline Self employed & 3.385 & 0.076 & 0.878 & 13.047 \\
\hline Peasant (Ref.) & & & & \\
\hline Ethnicity & & & & \\
\hline Makonde & 0.304 & 0.062 & 0.087 & 1.063 \\
\hline Makuwa & 0.370 & 0.122 & 0.105 & 1.306 \\
\hline Yao & 1.104 & 0.898 & 0.241 & 5.052 \\
\hline Others (Ref.) & & & & \\
\hline Number of children & & & & \\
\hline One & 1.712 & 0.164 & 0.802 & 3.652 \\
\hline Two & 1.315 & 0.489 & 0.606 & 2.851 \\
\hline Three or more & $\mathbf{2 . 1 4 8}$ & $\mathbf{0 . 0 4 2}$ & 1.030 & 4.483 \\
\hline None (Ref.) & & & & \\
\hline Access to health facility & & & & \\
\hline Yes & 2.072 & 0.353 & 0.445 & 9.637 \\
\hline No (Ref.) & & & & \\
\hline Distance to health facility & & & & \\
\hline Less than 5 kilometer & 0.297 & 0.113 & 0.067 & 1.330 \\
\hline More than 5 Kilometer (Ref.) & & & & \\
\hline Wealth index & & & & \\
\hline Poorest (Ref.) & & & & \\
\hline Poor & 0.542 & 0.668 & 0.033 & 8.904 \\
\hline Middle & $\mathbf{0 . 4 0 2}$ & $\mathbf{0 . 0 0 4}$ & 0.216 & 0.751 \\
\hline High & & & & \\
\hline & & & \\
\hline
\end{tabular}


The association between myths about preeclampsia and eclampsia and antenatal care services utilization.

A Chi-square done to show the relationship between Myths about preeclampsia and eclampsia and antenatal care services utilization then Bivariate and Multivariate logistic regression done. The findings showed those who had weak myths were $63 \%$ less likely to utilize ANC services compared to those who had strong myths. (AOR $=0.370$; $\mathrm{CI}=0.229$, 0.599; $\mathrm{P}=0.000)$. Furthermore, other factors showed no association. Table 9.

Table 9: Multivariate logistic regression between myths about preeclampsia and eclampsia and ANC utilization $\mathrm{N}=384$ 
Variable

Myths

Weak myths

$0.370 \quad 0.000$

0.229

0.599

Strong myths (Ref.)

Occupation

\begin{tabular}{lllll} 
Employed & 0.495 & 0.499 & 0.064 & 3.807 \\
\hline Unemployed & 0.696 & 0.435 & 0.279 & 1.732 \\
\hline Self employed & 3.816 & 0.050 & 1.002 & 14.533
\end{tabular}

Peasant (Ref.)

Ethnicity

\begin{tabular}{lllll} 
Makonde & 0.346 & 0.100 & 0.098 & 1.225 \\
\hline Makuwa & 0.411 & 0.169 & 0.116 & 1.460 \\
Yao & 1.467 & 0.620 & 0.323 & 6.660
\end{tabular}

Others (Ref.)

Number of children

\begin{tabular}{lllll} 
One & 1.540 & 0.258 & 0.729 & 3.254 \\
\hline Two & 1.214 & 0.622 & 0.562 & 2.623 \\
\hline Three or more & 1.772 & 0.125 & 0.853 & 3.680
\end{tabular}

None (Ref.)

Access to health facility
Yes
$\begin{array}{lll}1.955 & 0.394 & 0.418\end{array}$
9.139

No (Ref.)

Distance to health facility

Less than 5 kilometer

$\begin{array}{lll}0.291 & 0.108 & 0.065\end{array}$

1.310

More than 5 Kilometer (Ref.)

\section{Wealth index}

Poorest (Ref.)

\begin{tabular}{lllll} 
Poor & 0.407 & 0.539 & 0.023 & 7.185 \\
\hline Middle & 0.963 & 0.893 & 0.556 & 1.669 \\
\hline High & $\mathbf{0 . 3 6 1}$ & $\mathbf{0 . 0 0 1}$ & 0.194 & 0.672
\end{tabular}

\section{Discussion}

The results of the current study showed that $56.5 \%$ of the male partners and $55.5 \%$ of the pregnant women had inadequate knowledge about preeclampsia and eclampsia. The results of this study differ in findings of previous work done in Makole Dodoma [12 ] which Loading [MathJax]/jax/output/CommonHTML/jax.js 
revealed that $41 \%$ of the respondents had low knowledge. These differences might be due to geographical location where the study conducted as the current study conducted in Rural while the previous conducted in Urban, also it could be due to differences in the study population as the current study dealt with both pregnant women and their male partners while the previous study focused mainly on pregnant women who are attending Antenatal clinic and get health education regarding their status. This finding also differ with [13 ] findings which showed $60.0 \%$ of the respondents reported to have no knowledge.

The findings of the present study showed that those who had adequate knowledge about preeclampsia and eclampsia were $43.5 \%$ male partners and $44.5 \%$ pregnant women. The present findings seem to be in line with other research done in Same Moshi Tanzania [13 ] which found that $40 \%$ reported having adequate knowledge on preeclampsia and eclampsia [16].The findings might be due to the unplanned or absence of educational program regarding preeclampsia and eclampsia in the health facility and in the community.

Following the present results, previous studies have demonstrated that the local name was Rtjhodabaovadhan meaning that high blood pressure [14]. Another study was done in Southern Mozambique [17 ] reported that the local name for preeclampsia and eclampsia were falling disease, fainting disease, snake illness or childhood illness. This inconsistency of the findings might be due to the different study area and social demographic characteristics of the participants. Regarding the causes, the current study $37.2 \%$ of the participants reported that the cause was the devil living in the wild, sea, and big trees and $22.5 \%$ reported to be caused by frequency fever. These findings differ from the previous study [17 ] who reported the causes were mistreatment by in-laws, marital problems, and excessive thinking or worrying. These differences might be due to the cultural differences of the participants. Another important finding was that $10.5 \%$ of the respondents from the current study reported dizziness and Convulsions (kukwijula) were the signs and symptoms of preeclampsia and eclampsia. This is in line with the previous study [14 ] who reported the same findings. Drinking boiled green leaves was the local treatment of preeclampsia and eclampsia reported in the present study which accounts for $37.4 \%$ of the participants, special dance to expel demons/devils 24.7\%, burning leaves or incense (ubani) $18.9 \%$. These findings compared by the previous study [18] which showed that traditional treatment of preeclampsia were eating onions, drinking solution of the salt, bodily incisions and prayers. Another study [14] reported that the use of home remedies, spiritual treatment and alternative medicine. These findings imply that local treatment differs regarding culture, ethnicity and beliefs though there are some in common.

Antenatal care utilization among pregnant women who were in second and third trimester starting gestation age of 24 weeks and above. The results of the current study $64 \%$ of the premant women had ademate antenatal care service utilization. These results agree with Loading [MathJax]/jax/output/CommonHTML/jax.js

Page $24 / 31$ 
the findings of other study done in Jordan [19] in which $63.4 \%$ of the respondents had adequate ANC service utilization. It seems possible that these results might be due to an increasing number of health facilities in each village also the effort done by the government to ensure that every pregnant woman should be attended by the trained personnel as well as free services offered to pregnant women. A similar study was done Eastern Napel [20] which showed that $69 \%$ of the participants had higher antenatal care service utilization. Furthermore, the current study indicated that those who had inadequate ANC service utilization were 36\%. These results differ from the study done in Geita Tanzania [21] which showed the extremely low ANC attendance by 3.62\%. This inconsistency might be due to the social cultural beliefs, lack of knowledge regarding the importance of ANC utilization. It might be also the nature of the participants regarding their activities as the majority of the participants in Geita engaged in animal keeping and they tends to move from one place to another to fetch food for their animals. Therefore, this might be the reason for inadequate ANC utilization.

The current study determine the association between knowledge of preeclampsia and eclampsia towards ANC utilization which showed statistically significant association whereby those who had adequate knowledge about preeclampsia and eclampsia were 3 times more likely to utilize antenatal care service compared to those who had inadequate knowledge (P-value <0.05). Different from the study done in Napel [20] which showed that those respondents who had knowledge were 5 times more likely to have antenatal care utilization compared to those who did not have knowledge .These findings seemed to have difference since the current study was conducted in a developing country where the majority of their people had a primary level of education and were not much exposed to social media where can search information compared to the previous study which was conducted in a developed country. Therefore, women should be equipped with knowledge regarding their health and this could facilitate them to utilize antenatal care services. Knowledge can influence an individual to see the importance of seeking health services. The current study showed that only $43.5 \%$ of the male partners had adequate knowledge on preeclampsia and eclampsia and are the ones who are decision maker within the family level, therefore empowering men with adequate knowledge about reproductive health issues including preeclampsia and eclampsia will facilitate them to encourage their partners to attend ANC care. The knowledge of preeclampsia and eclampsia will also help the community to Identify the early signs and symptoms of the problem and take appropriate measures without delaying in seeking care as well as motivate them to attend antenatal care since they know the consequence of the problem and eventually reducing maternal morbidity and mortality rate due to preeclampsia and eclampsia in the country.

The findings showed that those who had weak myths were less likely to utilize ANC services compared to those who had strong myths $(P=0.000)$. These findings differ from the 
less likely to have antenatal care service utilization than those who did not believe tradition healers . These inconsistency results might be due to lack of adequate knowledge about preeclampsia and eclampsia though the participants had weak myths also resistance in behavior change. It might be also they did not see any benefit obtained through utilizing antenatal services. Furthermore, although the present study showed a number of respondents who had strong myths are low but still more effort is needed to dispel myths and misconceptions in the community at large and ensure all pregnant women are utilizing antenatal services for the benefit of both mother and unborn baby.

\section{Strength and limitation of the study.}

\section{Strength}

The researcher managed to conduct study in all selected district despite of poor infrastrucres.

\section{Limitations.}

This study conducted in Mtwara region involved four district and it was about knowledge and myths regarding preeclampsia and eclampsia therefore it might not reflect the whole country due to cultural diversity as in every region have their own myths and cultural differences.

\section{Conclusion}

The overall knowledge about preeclampsia and eclampsia was low. Majority of the participants had weak myths although the different with those who had strong myths was small. The majority of the pregnant women utilized antenatal care services. Furthermore, findings showed that those with adequate knowledge had adequate antenatal services utilization. Moreover, those who had strong myths found to have antenatal care services utilization. Therefore, the community should be educated regarding the facts about preeclampsia and eclampsia in order to dispel the available Myths and misconceptions and ensure ANC services utilization for all pregnant women inorder to prevent complications of pregnancy.

\section{List Of Abbreviations}

ANC-Antenatal clinic, AIDS - Acquired Immuno Deficiency Syndrome, BEmONC - Basic Emergency Obstetric and Newborn Care., CEMONC - Comprehensive Emergency Obstetric and Newborn Care., DCDistrict council, HBM- Health belief model, HELLP - Hemolysis, Eleveted Liver enzyme, Low Platelet count., H/F- Health facility, HSSP - Health Sector Strategic Plan, MDGs - Millennium Development Goals, MOHsw - Ministry of Health and Social warefare, PCA - Principal component analysis, RCH - 
Demographic Health Survey, TC- Town council, UDOM - University of Dodoma, URT - United Republic of Tanzania, UNFPA - United Nation Fund for Population Activities, UNICEF- United Nation International Children emergence Fund, USA - United State of America, WHO - World Health Organization

\section{Declarations}

\section{Acknowledgements}

My sincere gratitude goes to the University of Dodoma, Regional administrative secretary of Mtwara region, Districts administrative secretaries of Mtwara DC, Newala, Nanyumbu and Masasi DC, all Districts executives' directors (DED), Ward Executive officers (WEO) and Village leaders who granted me a permission to conduct this study in their respective areas. I would also like to extend my deep appreciation and sincere gratitude to my supervisors, my research assistants, and the study participants for their willingness to participate in this study. I would also wishes to thank Dr. Secilia K. Ng weshemi and Dr. Julius Ntwenya for support and encouragement throughout the course of this study.

\section{Author's contributions}

SMK senior supervisor assisted in data analysis, NG, FM and AL contributed to the interpretation of data. All authors read, commented on and approved the final manuscript.

\section{Funding}

There was no external source of funding used for this study.

\section{Availability of data and materials}

The dataset used and /or analyzed during the current study are available from corresponding author on reasonable request.

\section{Ethical approval and consent to participate}

Ethical clearance was obtained from University of Dodoma ethics and committee before commencing the data collection. Also permission to conduct the study obtained from the Regional administrative secretary of Mtwara, District Administrative secretaries of Mtwara District council, Newala, Nanyumbu and Masasi DC. The permission letters obtained were presented to Ward Executive officers, and Village leaders who granted me a permission to conduct study in their respective areas. Written consent was obtained from each participant before data collection.

\section{Consent for publication}

Not applicable 
The author declares that there was no conflict of interest.

\section{Author details}

${ }^{1}$ Department of clinical Nursing- Division of Nursing and Midwifery services Ministry of health community development, Gender, Elderly and Children Box 743, Dodoma Tanzania. ${ }^{2}$ Acting Depute Principal Collage of Health Science, University of Dodoma Box 295 Dodoma Tanzania, ${ }^{3}$ Department of Public Health, University of Dodoma Box295 Dodoma Tanzania, ${ }^{4}$ Department of health services, University of Dodoma Box 295 Dodoma Tanzania and ${ }^{5}$ Department of Nursing and Midwifery, University of Dodoma Box 295 Dodoma Tanzania.

\section{References}

1. WHO, UNICEF, UNFPA, The World Bank UN. Trends in Maternal Mortality: 1990 to 2013;; 2014.

2. WHO UNICEF, UNFPA WBG and the UN, Division P. Trends in maternal mortality: 1990 to 2015: 2015.

3. TDHS. Demographic and Health Survey and Malaria Indicator Survey.; 2015.

4. Konar H. DC Dutta's Textbook of Obstetrics. 8th editio. New Delhi London: Jaypee Brothers Medical Publisher (P) Ltd; 2015.

5. Ajah L, Ozonu N, Ezeonu P, Lawani L, Obuna J, Onwe E. The feto-maternal outcome of preeclampsia with severe features and eclampsia. J Clin Diagn Res. 2016.

6. MOHsw. Health Sector Strategic Plan July 2015-June 2020;; 2015.

7. WHO. Maternal mortality [Internet]. Available from http//www.who.int/mediacentre/factsheets/fs348/en/. 2016.

8. Ogunjimi L, Ibe T, Ikorok M. Curbing maternal and child mortality. Int J Nurs midwifery. 2012;4(33-9).

9. Iliyasu Z, Abubakar I, Galadanci H, Aliyu M. Birth preparedness, complication readiness and fathers' participation in maternity care in a northern Nigerian community. Afr J Reprod Heal. 2010;14(1):2132.

10. Bhatta D. Involvement of males in antenatal care, birth preparedness, exclusive breast feeding and immunizations for children in Kathmandu, Nepal. BMC Pregnancy Childbirth. 2013.

11. Nanjala M, Wamalwa D. Determinants of Male Partner Involvement in Promoting Deliveries by Skilled Attendants in Busia, Kenya. Glob J Heal. 2012.

12. Savage AR, Hoho L. Knowledge of pre-eclampsia in women living in Makole Ward, Dodoma, Tanzania . 2016;16(2):412-419.

13. Eze ED, Barasa A, Adams MD, Rabiu KM, Sulaiman SO, Ponsiano N. Determination , knowledge and prevalence of pregnancy-induced hypertension / eclampsia among women of childbearing age at Same District Hospital in Tanzania. 2018;10(February):19-26. doi:10.5897/IJMMS2017.1343

14. Khowaja AR, Qureshi RN, Sheikh S, et al. Community 's perceptions of pre-eclampsia and eclampsia in Sindh Dakictan. a nualitativo ctudv Reprod Health. 2016;13(Suppl 1). doi:10.1186/s12978-016- 
0136-x

15. URT. 2012 POPULATION AND HOUSING CENSUS. National Bureau of Statistics Microfinance Dar Es Salaam and Office of Chief Government Statistician President's Office, Finance, Economy and Development Planning Zanzibar.; 2013.

16. Zuo tey chiao, Teng see poh, Keng soon lean, Jummaat fauziah bt. Knowledge of preeclampsia among antenatal women in atertiary referral teaching hospital. Malaysian J Nurs. 2016;7(2):8-13.

17. Boene H, Vidler M, Sacoor C, et al. Community perceptions of pre-eclampsia and eclampsia in southern Mozambique. Reprod Health. 2016;13(Suppl 1). doi:10.1186/s12978-016-0135-y

18. Akeju DO, Vidler M, Oladapo OT, Sawchuck D, Qureshi R, Dadelszen P Von. Community perceptions of pre-eclampsia and eclampsia in Ogun State, Nigeria: a qualitative study. Reprod Health. 2016;13(Suppl 1). doi:10.1186/s12978-016-0134-z

19. Hijazi HH, Alyahya MS, Sindiani AM, Saqan RS, Okour AM. Determinants of antenatal care attendance among women residing in highly disadvantaged communities in northern Jordan: a cross-sectional study. 2018:1-18.

20. Deo KK, Paudel YR, Khatri RB, et al. Barriers to utilization of antenatal care services in eastern nepal. 2015;3(August):1-7. doi:10.3389/fpubh.2015.00197

21. Konje ET, Tito M, Magoma N, et al. Missed opportunities in antenatal care for improving the health of pregnant women and newborns in Geita district, Northwest Tanzania. 2018:1-13.

\section{Figures}






\section{Figure 1}

knowledge on pre eclampsia and eclampsia among pregnant women and their male partners

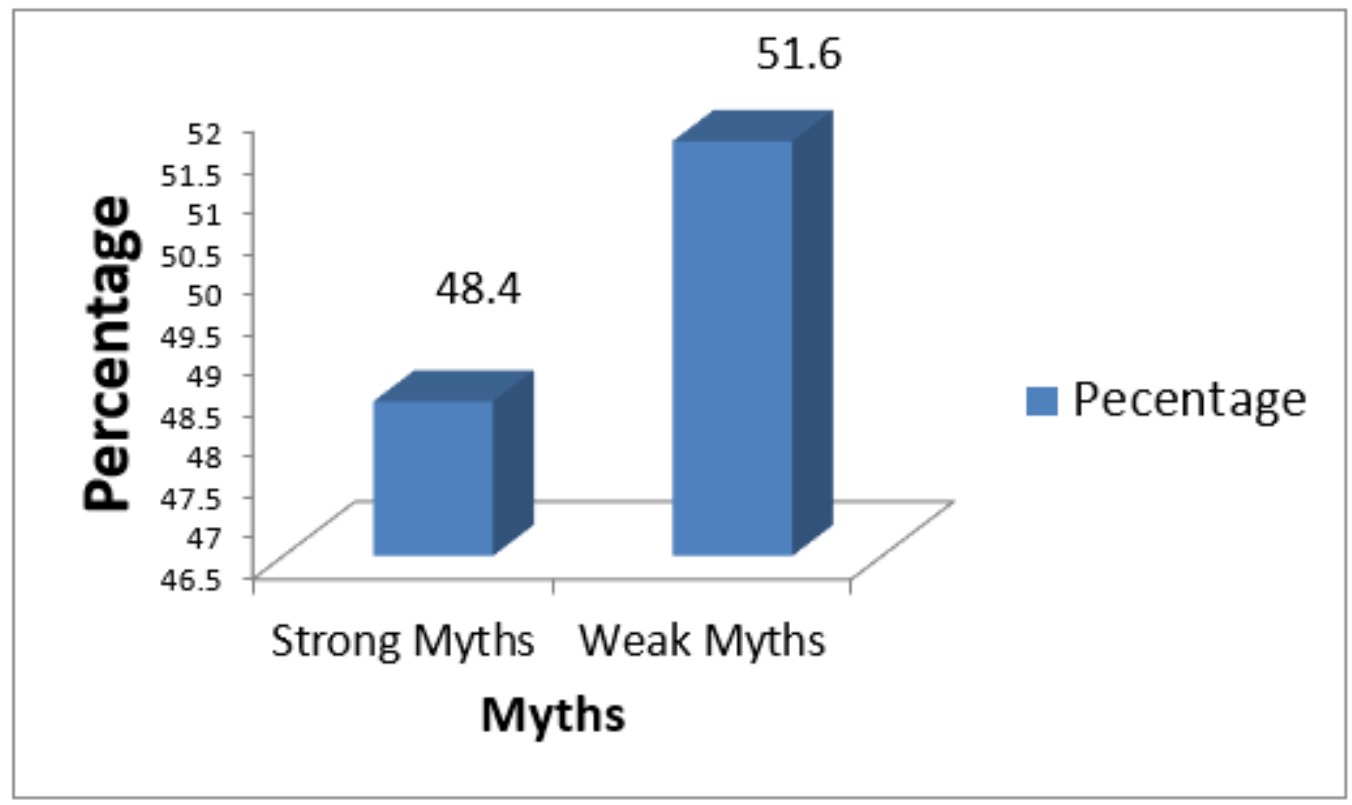

Figure 2 


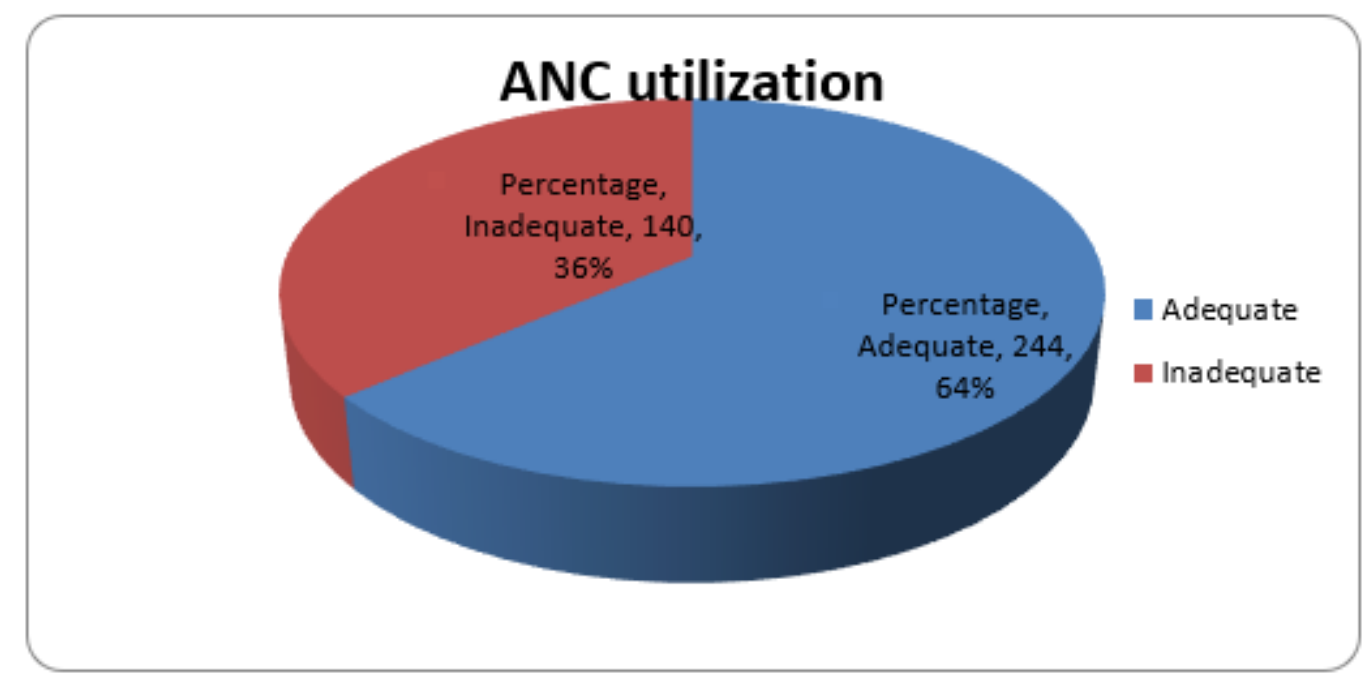

\section{Figure 3}

Antenatal care service utilization.

\section{Supplementary Files}

This is a list of supplementary files associated with this preprint. Click to download.

- Appendix.docx 